\title{
The promise of organ and tissue preservation to transform medicine
}

\author{
Sebastian Giwa ${ }^{1-3,46}$, Jedediah K Lewis ${ }^{1,46}$, Luis Alvarez ${ }^{4-6}$, Robert Langer ${ }^{7}$, Alvin E Roth ${ }^{8}$, George M Church ${ }^{9}$, \\ James F Markmann ${ }^{10}$, David H Sachs ${ }^{11}$, Anil Chandraker ${ }^{12,13}$, Jason A Wertheim ${ }^{14,15}{ }^{(D)}$, Martine Rothblatt ${ }^{16}$, \\ Edward S Boyden ${ }^{17}$, Elling Eidbo ${ }^{18}$, W P Andrew Lee ${ }^{19}$, Bohdan Pomahac ${ }^{20}$, Gerald Brandacher ${ }^{19}$, \\ David M Weinstock ${ }^{21}$, Gloria Elliott ${ }^{22}$, David Nelson ${ }^{23}$, Jason P Acker ${ }^{24,25}$, Korkut Uygun ${ }^{26}$, Boris Schmalz ${ }^{1,27}$, \\ Brad P Weegman ${ }^{1,2}$, Alessandro Tocchio ${ }^{1,28}$, Greg M Fahy ${ }^{29}$, Kenneth B Storey ${ }^{30}$, Boris Rubinsky ${ }^{31}$, John Bischof ${ }^{32}$, \\ Janet A W Elliott ${ }^{24,33}$, Teresa K Woodruff ${ }^{34}$ (D, G John Morris $^{35}$, Utkan Demirci ${ }^{28,36}$, Kelvin G M Brockbank ${ }^{37}$, \\ Erik J Woods ${ }^{3,25,38}$, Robert N Ben ${ }^{39}$, John G Baust ${ }^{40}$, Dayong Gao ${ }^{25,41}$, Barry Fuller ${ }^{42}$, Yoed Rabin ${ }^{43}$, \\ David C Kravitz ${ }^{44}$, Michael J Taylor $2,43,45$ (I) \& Mehmet Toner ${ }^{26}$
}

The ability to replace organs and tissues on demand could save or improve millions of lives each year globally and create public health benefits on par with curing cancer. Unmet needs for organ and tissue preservation place enormous logistical limitations on transplantation, regenerative medicine, drug discovery, and a variety of rapidly advancing areas spanning biomedicine. A growing coalition of researchers, clinicians, advocacy organizations, academic institutions, and other stakeholders has assembled to address the unmet need for preservation advances, outlining remaining challenges and identifying areas of underinvestment and untapped opportunities. Meanwhile, recent discoveries provide proofs of principle for breakthroughs in a family of research areas surrounding biopreservation. These developments indicate that a new paradigm, integrating multiple existing preservation approaches and new technologies that have flourished in the past 10 years, could transform preservation research. Capitalizing on these opportunities will require engagement across many research areas and stakeholder groups. A coordinated effort is needed to expedite preservation advances that can transform several areas of medicine and medical science.

The global shortage of organs for transplantation has long been recognized as a major public health challenge, and the World Health Organization (Geneva) estimates that only $10 \%$ of the worldwide need for organ transplantation is being met ${ }^{1}$. The data suggest that the organ shortage is among the greatest crises facing biomedicine today. Although few estimates are available of the total number of patients who could benefit from organ transplantation if supply constraints were removed, the commonly cited transplant waiting lists clearly fail to capture the organ shortage's true magnitude. For example, the number of patients added to US transplant waiting lists each year-roughly 50,000 - is dwarfed by the $\sim 730,000$ annual US deaths attributable to end-stage organ disease (Fig. 1) ${ }^{2,3}$. As one example, the true need for heart transplantation in the United States has been estimated at more than ten times the heart transplant waiting list ${ }^{4,5}$. It has been suggested that with all supply constraints removed, organ replacement could theoretically prevent $>30 \%$ of all deaths in the United States-doubling the average person's likelihood of living to 80 years of age ${ }^{6-8}$. Similarly, estimates based on incidence of diseases that are potentially addressable by on-demand organ replacement place the true need at millions of transplant organs per year in the United States and Europe combined ${ }^{9}$.

The organ shortage is markedly worse in many other countries. For instance, the continent of Africa holds $16 \%$ of the world's population but performs only $0.5 \%$ of its organ transplants (Fig. 2). Moreover, in some of the countries with the least access to transplantation, a substantial fraction of transplant procedures are actually instances of transplant tourism ${ }^{10}$. In Pakistan, for instance, up to two-thirds of kidney transplants in 2005 are estimated to have been performed on foreigners ${ }^{10,11}$. The practice has widely been considered problematic because it creates opportunities for organ commodification and exploitation of vulnerable populations; the Declaration of Istanbul, signed by 157 representatives from countries across the globe, condemns the practice ${ }^{12}$. Healthcare infrastructure, national wealth, and sometimes cultural factors can each play a major role in the disparities in access to transplantation internationally. Yet over time, easing logistical burdens and increasing supply can lower the barriers to development of transplantation infrastructure ${ }^{4,5}$, and as discussed below, to equitable access to transplantation within countries.

The above considerations should place technologies that can substantially increase the availability of transplant organs at the top of our scientific priority list. Moreover, the need for these technologies is shared with many other major public health challenges. Banking of viable organs and tissues can transform cancer treatment for young 


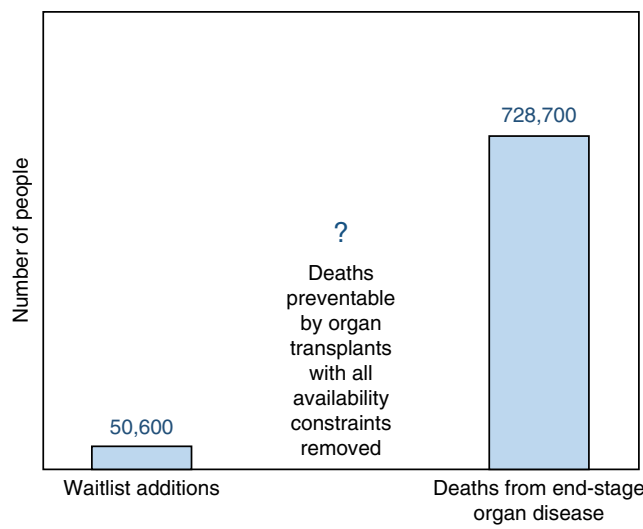

Figure 1 The true lifesaving potential of organ transplantation. The roughly 50,000 US patients added to transplant waiting lists in 2011 were outnumbered over 14 -fold by those who died from end-stage organ disease (http://www. perfusix.com/impact-of-ex-vivo.html), without counting cases where malignancies could have been treated with organ replacement ${ }^{168}$. This suggests that the true size of the organ shortage could be many times larger than is reflected by transplant waiting lists (currently 120,000 US patients).

patients and have a dramatic impact on precision medicine and research on diseases such as heart disease, cancer, and Alzheimer's disease. Ballooning costs in drug discovery are exacerbated by poor availability of human tissue models, which in many cases could provide more valuable data than the animal models currently used. Tissue transplantation faces enormous logistical barriers in emergency care because tissue is needed on such short notice. These challenges are magnified in contexts where large numbers of patients require care, such as the treatment of wounded service members and civilian victims of natural disasters or terrorist attacks. In these and many other areas, adequate techniques and treatments often already exist. However, their use is pervasively handicapped by the limited availability of organs and tissues, which are among the most precious resources in research and medicine. The aggregate toll on human health attributable to causes that could be addressed by increasing organ and tissue availability makes this problem one of the most important healthcare challenges of this era.

Developing an organ and tissue supply that can meet the healthcare demands of the twenty-first century requires the development of solutions to twin challenges: first, having enough of these lifesaving resources; and second, having the means to store and transport them for a variety of applications, each with distinct but overlapping logistical needs. Having enough organs and tissues to meet public health needs has been the subject of extensive efforts in science, medicine, and public policy aiming to increase organ donation ${ }^{13,14}$, improve donor organ utilization ${ }^{15-18}$, and gain the understanding needed to engineer laboratory-grown tissues ${ }^{19}$, bio-artificial organs ${ }^{20,21}$, and 'humanized' animal donor organs for transplantation ${ }^{22,23}$. The success of these efforts is intertwined with meeting the second challenge: preserving organs and tissues during procurement (or manufacturing), storage, transport, and other steps of the supply chain in order to meet logistical needs.

Despite its importance, the preservation challenge has received relatively little attention from funding agencies, the research community, and the general public. Taken together, preservation constraints place widespread burdens on efforts to use organs and tissues in transplantation, regenerative medicine, and research. Yet, although $>80 \%$ of the budget of the US National Institutes of Health (NIH) goes to institutes with missions tied to unmet preservation needs ${ }^{24}$, and numerous other science agencies and stakeholder groups stand to benefit from preservation advances, no funding body has been charged with overcoming the remaining technical challenges common to the preservation of organ and tissue systems. As a result, the past half-century has seen only incremental and relatively ad hoc investments to advance preservation technologies.

By overcoming these institutional barriers and facilitating coordinated and cross-disciplinary research, it is now possible to dramatically accelerate progress in organ and tissue preservation using existing knowledge from a diverse array of fields. The past decade of progress has allowed us to understand and intervene in human physiology at the tissue and organ level as never before, with breakthroughs in nanotechnology, sequencing, imaging, omics approaches, and other areas. These technologies can be used to build on proofs of principle for organ cryopreservation $6,7,25-28$, discoveries from organisms that can enter 'suspended animation' at subzero temperature ${ }^{29-32}$, rapid advances in perfusion technologies ${ }^{33-41}$, and other advances.

In light of these opportunities, a growing coalition of scientists, clinicians, policymakers, advocacy groups, academic institutions, and industry representatives is assembling to accelerate progress in organ and tissue preservation. This has led to an extensive dialog spanning more than a year, which has included the first global Organ Banking Summit at Stanford, NASA Research Park, and other locations ${ }^{7}$, a US National Science Foundation (NSF)-supported Roadmap to Organ Banking and Bioengineering Workshop ${ }^{6}$, a meeting hosted with the Defense Advanced Research Projects Agency (DARPA) leadership at the US Military Academy at West Point, New York, on a potential 'Organs on Demand' research program, a White House roundtable on organ banking and bioengineering, and a symposium and roundtable on emerging organ preservation technologies on Capitol Hill. At these events, stakeholders have begun to outline the vast public health needs, remaining technological challenges, institutional and infrastructural barriers, and untapped research opportunities surrounding efforts to eliminate preservation constraints on the use of organs and tissues in biomedicine ${ }^{25}$. These efforts aim to facilitate the advancement of preservation platforms allowing us to transport, repair, assess, bank, and even enhance the health and function of organs and a variety of tissues used in research and medicine.

The diversity of authors of this article, with expertise spanning organ and tissue procurement and transplantation, preservation research, bioengineering, economics, trauma care, and regenerative medicine, reflects the breadth of need in this area-and the widespread concern that until preservation breakthroughs are pursued aggressively, many medical technologies will not come close to reaching their lifesaving potential. In the sections that follow, we describe how organ and tissue preservation can meet a variety of major public health needs. We also outline recent discoveries indicating that a revolution in organ and tissue preservation is now achievable, propose a novel paradigm for preservation involving convergence of a family of existing approaches, and describe how technologies have the potential to make a new generation of preservation technologies feasible. Finally, we suggest ways that the research community can overcome institutional barriers that hinder advances, and we highlight recent progress toward a coordinated research effort.

\section{The unrealized potential of organ transplantation}

Organ transplantation is one of the most impressive medical achievements of the past century. In the past 25 years, it has added over two million life-years to patients in the United States alone ${ }^{42}$. In the 60 years since its inception, researchers have made strides in drug-mediated 


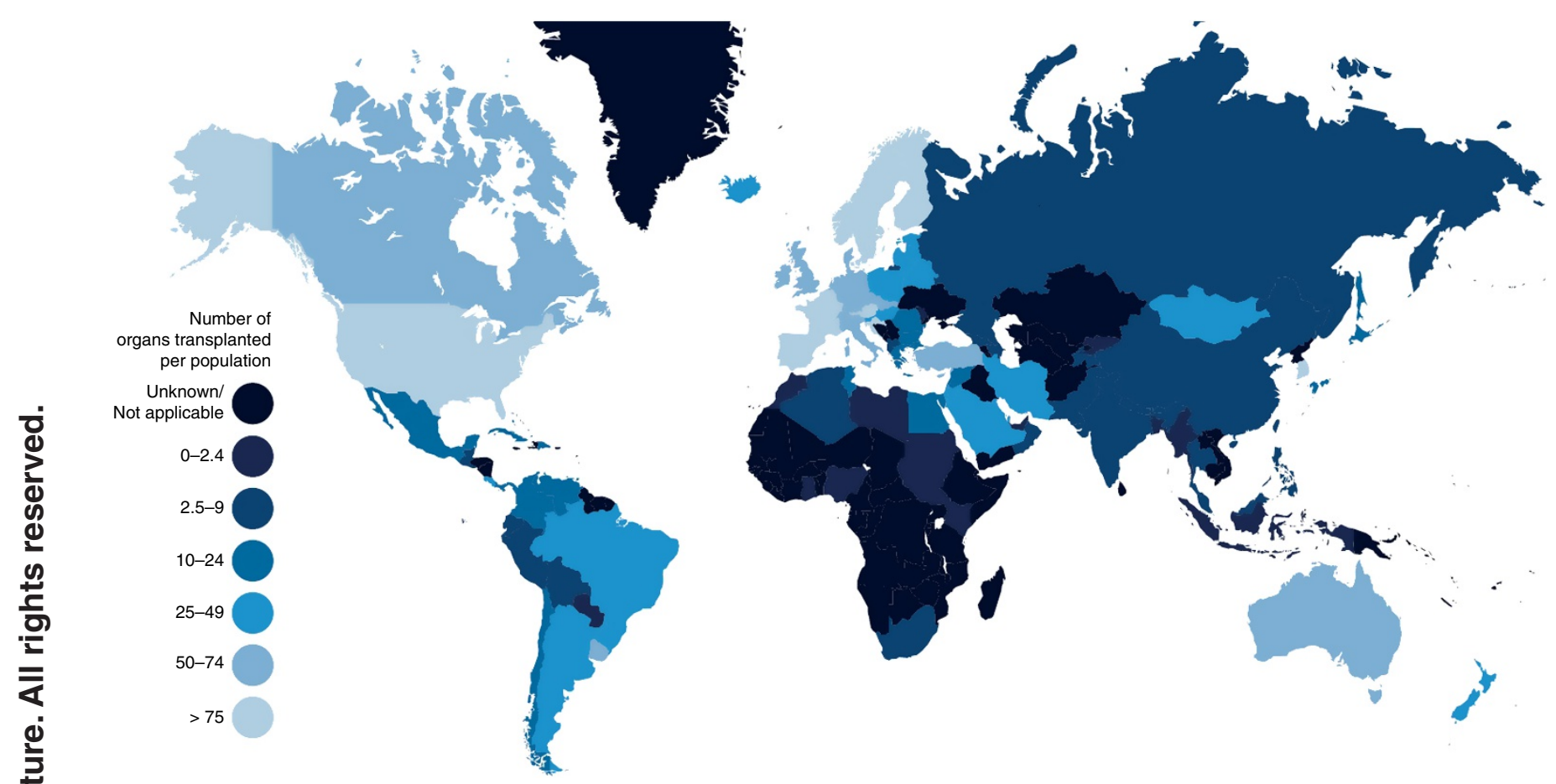

Figure 2 The global unmet need for transplantation greatly exceeds that of the United States (see Fig. 1), which contains roughly $4 \%$ of the world's population but performs $25 \%$ of its organ transplants. By comparison, the continent of Africa contains roughly $16 \%$ of the world's population but performs fewer than $0.5 \%$ of its organ transplants (http://www.transplant-observatory.org/summary/; https://esa.un.org/unpd/wpp/publications/files/key_ findings_wpp_2015.pdf).

immunosuppression ${ }^{43}$, achieved increasingly complex transplant operations ${ }^{4-46}$, and begun (recently) to move immune tolerance induction therapies into the clinic $^{47-50}$.

Yet access to transplantation and its efficacy are still fundamentally constrained. For the patients in need of organ replacement who are lucky enough to be placed on a transplant waiting list, morbidity and mortality are substantial ${ }^{51,52}$; one in five waiting-list patients in the United States will die or become too sick for a transplant before receiving a new organ ${ }^{52}$. In part because of the rare conditions that must exist for organs to be suitable for recovery and transplantation, today only $0.3 \%$ of those who die in the United States become organ donors 3,53 . Ideally, one organ donor can provide up to eight lifesaving organs to patients on transplant waiting lists, yet on average roughly only three are transplanted-despite decades of progress advancing organ procurement protocols and heroic efforts by organ procurement organizations ${ }^{2,53}$. Although advances in immunosuppression have greatly increased transplant success rates and graft survival ${ }^{54-56}$, half of these organs fail within 10 years of being transplanted, including as many as $75 \%$ of intestines and lungs (Fig. 3) ${ }^{57}$. To delay rejection, transplant recipients must adhere to lifelong immunosuppressant drug regimes, the side effects of which put patients at increased risk for life-threatening infections as well as cancer and other major age-related diseases ${ }^{58}$. Meanwhile, children, ethnic minorities, and other vulnerable patient populations have markedly reduced access to transplantation ${ }^{59-62}$. The toll on the economy of the unmet need for transplantation is immense; for instance, the worldwide cost of treating end-stage renal disease totals over $\$ 1$ trillion in the course of a decade ${ }^{63}$, with over $\$ 40$ billion spent by the United States in 2009 alone $^{64}$.

These problems are fueled by severe logistical constraints related to organ preservation limits. Although leaps forward in machine perfusion $^{33-41,65-67}$, organ cryopreservation ${ }^{26,27,68}$, understanding scientific mechanisms of ischemic injury and metabolic regulation $^{29-32,41}$, and other areas have created a blueprint for transforming organ preservation, today maximum clinical organ preservation times are measured in hours, varying according to the organ transplanted, and necessitate transplantation almost immediately after the organ is recovered (http://www.nedonation.org/donation-guide/organ/ acceptable-ischemic-times). Organs are rushed to their destinations, often by jet, or by helicopter flight straight to a landing pad on the transplant center rooftop. Speed is essential when arranging and performing the transplant surgery, leaving little room to adapt procedures to individual circumstances or deal with complications. Lengthy operations must be performed day or night with little advance warning. These factors contribute to high costs for organ transplantation, which in the United States can average well over \$1 million (e.g., heart, intestine, and double lung transplant ${ }^{69}$. During transplantation organs are exposed to a continuous barrage of inflammation and oxidative stress, both before and after organ procurement from the donor, contributing to immune rejection, delayed graft function, and other complications that harm transplant outcomes.

Donor organs and recipients must be matched over relatively short geographic distances and time periods, often resulting in the use of organs that are immunologically not well-matched to recipients. This puts patients at increased risk for organ rejection and contributes to the need for intensive immunosuppressive regimens ${ }^{70}$. The increased rate and severity of rejection limits organ life span, further exacerbating the organ shortage; within several years of transplantation, many patients are in need of a new organ all over again ${ }^{57}$. Limited matching distances leave waiting-list patients from different regions with unequal access to transplant organs as supply and need vary. These imbalances disproportionately affect patients with fewer resources, who cannot relocate to join more favorable waiting lists ${ }^{59,71}$. 


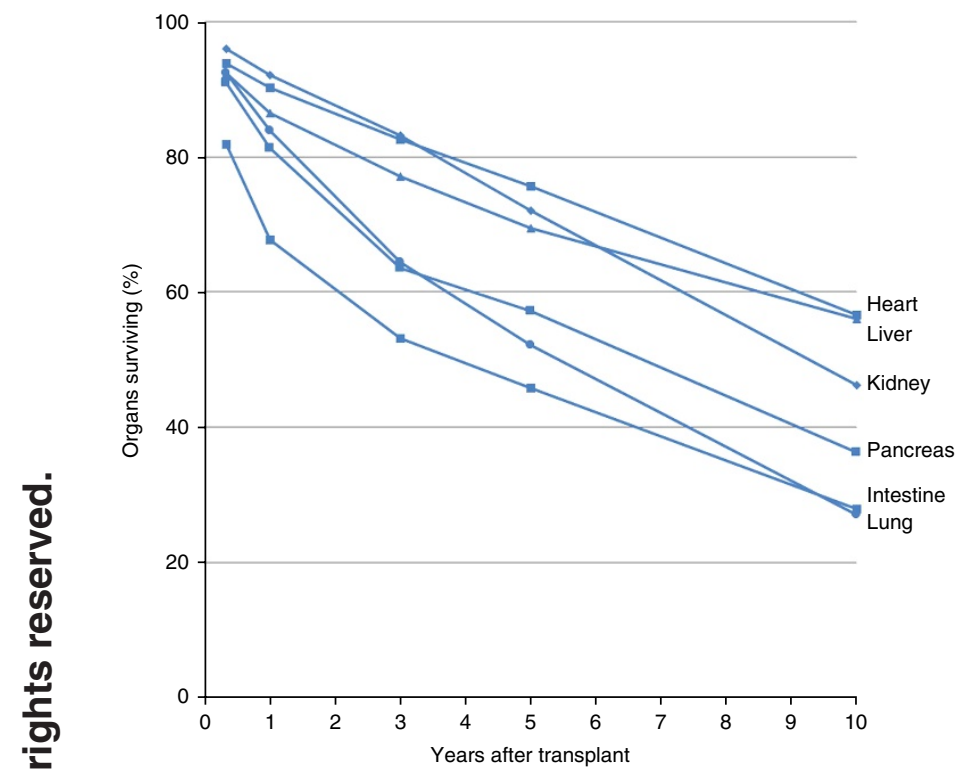

Figure 3 10-year graft survival for each of the six vital organs currently transplanted (single-organ, deceased donor transplant)49.10-year survival rates for organs range from slightly over 50\% (hearts and livers) to slightly over 25\% (lungs and intestine). These data indicate that ensuring transplant organ quality and reducing susceptibility to chronic rejection are still major challenges in transplantation. Preservation advances present diverse opportunities to meet these challenges (Table 2).

Matching limitations often fall hardest on populations with small pools of potential matching donors, particularly among children and ethnic minorities ${ }^{60,61,72,73}$.

Meanwhile, narrow windows of opportunity for organ assessment, allocation, and transplantation fuel organ discard. Organs are offered to individual patients on a waiting list, whose doctors must decide whether to recommend transplantation based on limited information about the organ's suitability for transplantation; with little information on the organ's functional status, some patients may turn it down when the donor's history or other indicators are dubious, waiting until a less risky organ is (hopefully) made available ${ }^{52}$. Even a functional, transplantable organ may be turned down by the transplant centers of one patient after another until the organ's preservation limits prevent further matching ${ }^{41,74}$. Each year, this phenomenon contributes to thousands of abdominal organs being discarded ${ }^{74,75}$, and the majority of thoracic organs from donors ( $70 \%$ of heart and $80 \%$ of lung offers) going untransplanted ${ }^{2,76}$. Most likely, many of these organs could have been successfully transplanted under the right circumstances ${ }^{41,77-79}$. The resulting impact on waiting-list patients is profound. In the United States, if just $10 \%$ of the number of donor hearts currently left unused were transplanted, the number of additional hearts made available would equal the number of waiting-list patients who currently die or become too sick for a transplant before receiving one (Table $\mathbf{1})^{75}$.

\section{Organ transplantation without preservation constraints}

A successful large-scale organ preservation research effort would create a very different world for organ transplantation, creating a breadth of new capabilities that could make more organs available, improve transplant outcomes and mitigate risks, decrease costs, and complement and accelerate the development of other biomedical technologies that can alter the landscape of transplantation in the coming years (Table 2). For instance, preservation advances can build on promising strategies that use perfusion circuits to mimic healthy physiological conditions ${ }^{38,80,81}$. These platforms can allow the organ to recover from cellular stress and tissue injury during donor death and organ procurement, which can contribute to inflammation and organ rejection following transplantation ${ }^{80-83}$, and also enable therapeutic intervention before transplantation ${ }^{83-87}$. The advent of ex vivo organ perfusion shows promise to make larger pools of donor organs available by enabling rehabilitation of organs that would otherwise be unsuitable for transplantation ${ }^{38,41,82}$.

Perfusion-based preservation could be harnessed as a platform to functionally enhance organs. Any of several existing techniques might be part of the process to condition organs for transplantation or subsequent steps of the preservation process ${ }^{83}$; these include drug-mediated immunomodulation to apply treatments that block or alter sites recognized by the recipient's immune system to mitigate rejection ${ }^{84,85}$; gene therapy ${ }^{86,87}$; antisense, or RNA interference. Similar interventions could even be used to improve organs' health and function, making them in some ways healthier in the recipient than they were in the donor. For instance, perfusion platforms have allowed the 'defatting' of livers after removal in animal models of steatosis ${ }^{41}$, showing promise for mitigation or reversal of organ degeneration during the donor's lifetime that could otherwise affect both transplant outcomes and, later, the recipient's health ${ }^{15,88,89}$.

Perfusion platforms can allow transplantation of many organs that would otherwise be deemed too risky to transplant by allowing their health and function to be assessed outside the body $37,41,87,90,91$. For example, it has been proposed by the National Heart Lung and Blood Institute and found by other studies that many hearts that would provide substantial survival benefits to patients are going unused, largely owing to a lack of reliable methods to assess their suitability for transplantation ${ }^{79,92}$. By allowing organ function to be observed after procurement, perfusion platforms are enabling the investigation of new biomarkers that predict organ health and transplantability ${ }^{93-96}$

A variety of preservation breakthroughs could enable transport of organs over longer distances ${ }^{7,40}$, opening up many new possibilities for organ allocation and therapeutic intervention. With distance no longer a factor in donor-recipient matching, closer matches could be achieved. This could decrease rejection and the need for immunosuppression ${ }^{70}$ and extend graft life span, while increasing access to transplantation for disadvantaged patient populations $s^{60,73}$. Organs could also be routed through specialized facilities, which have been suggested by several groups as a way to make technically challenging assessment, repair, functional augmentation, or banking procedures a clinical reality ${ }^{7,87,91}$. Thus, approaches that today

Table 1 Summary picture for four vital organs from deceased donors

\begin{tabular}{|c|c|c|c|c|}
\hline Vital organ & Number transplanted ${ }^{75}$ & $\begin{array}{l}\text { Percentage of donor organs not } \\
\text { transplanted } 75\end{array}$ & $\begin{array}{l}\text { HLA compatibility used in matching } \\
\text { algorithms? }{ }^{169}\end{array}$ & $\begin{array}{l}\text { Ratio of unused organs to waiting list } \\
\text { patients removed for death or illness } 53\end{array}$ \\
\hline Lung & 3,019 & 81 & No & $32: 1$ \\
\hline Liver & 5,942 & 27 & No & $3: 4$ \\
\hline
\end{tabular}


Table 2 Preservation enables key transplant capabilities

\begin{tabular}{|c|c|}
\hline Goal & Capabilities \\
\hline \multirow{5}{*}{$\begin{array}{l}\text { Increasing pool of } \\
\text { donor organs }\end{array}$} & Reducing organ discard \\
\hline & Rescuing marginal organs \\
\hline & Decreasing costs of transplantation \\
\hline & New matching approaches in deceased donation \\
\hline & Successive organ transplants in case of graft dysfunction \\
\hline \multirow{7}{*}{$\begin{array}{l}\text { Enhancing transplant } \\
\text { viability and function }\end{array}$} & Repairing organ injury during removal and transport \\
\hline & Assessing organ function before transplant \\
\hline & Enabling new immune-tolerance-induction strategies \\
\hline & Transmissible disease screening for donors and organs \\
\hline & $\begin{array}{l}\text { Augmenting organs (e.g., gene therapy, } \\
\text { immunomodulation) }\end{array}$ \\
\hline & $\begin{array}{l}\text { New donor-recipient compatibility assessment } \\
\text { methods }\end{array}$ \\
\hline & Preventing ischemic injury during transplant \\
\hline \multirow{2}{*}{$\begin{array}{l}\text { Expanding transplantation } \\
\text { access }\end{array}$} & Extending live kidney donation chains \\
\hline & $\begin{array}{l}\text { Enabling recipients with acute disease or trauma } \\
\text { Flexible scheduling of transplant surgeries }\end{array}$ \\
\hline Galvanizing research & $\begin{array}{l}\text { Accelerating progress in cryobiology and preservation } \\
\text { Accelerating progress in humanized xenotransplantation } \\
\text { Accelerating progress toward lab-grown organs }\end{array}$ \\
\hline
\end{tabular}

would not be seriously considered could become practical and fruitful areas of innovation.

Preservation breakthroughs could allow organs to be banked in a state of suspended animation at subzero temperatures ${ }^{7,25-27,68}$, protected from ischemic injury and the damaging environment of the deceased donor body, for periods long enough to perform any assay needed on patients or tissue samples. This would enable more thorough screening for malignancies and transmissible diseases, such as rabies ${ }^{97,98}$ and $\mathrm{HIV}^{99}$. Currently, disease transmission rates in organ transplantation, although $<1 \%$, are estimated to be on the order of 10,000 times higher than in blood transfusion, where a maximum shelf life of 5-6 weeks enables the use of lengthy disease-screening assays ${ }^{100}$. Organ banking could also provide many new opportunities for matching, by uncoupling organ allocation from the narrow windows of time that currently constrain it.

Importantly, organ banking could prevent unnecessary loss of life by allowing any organs not immediately matched to be saved until a match could be found. This would make transplantation available to more patients, not only by offering a complementary organ supply but also by shifting the risk-benefit balance for patients and their transplant centers away from refusing transplantable organs. Primary graft dysfunction is a major cause of morbidity and mortality following transplantation ${ }^{101-103}$, and roughly $50-75 \%$ (depending on the organ transplanted) of all graft failure in the first year after transplantation occurs within the first 3 months ${ }^{57}$. Banked organs could provide a 'backup' supply in the case of early failure of the initial transplant; in cases where multiple matching organs were available, often multiple successive transplants would be feasible if the initial transplant fails. Thus, even when an organ individually carries a risk of early graft failure, the alternative supply of banked organs could substantially derisk the overall process of transplantation, allowing transplant centers to accept the organ with substantially decreased patient risk.

Organ banking could also make transplantation a lifesaving treatment for heart attack victims, trauma patients, victims of accidental poisoning, and others with acute vital organ failure. For these patients, matching transplant organs need to be available within extremely short time periods, necessitating off-the-shelf solutions. Banking the substantial fraction of organs that go unused in the current allocation system could be lifesaving for these patients. The public health benefits of banking organs for emergency surgery could be vast; traumatic injury accounts for more deaths among adolescents and children than all other causes combined ${ }^{104}$. Similarly, an International Society of Heart and Lung Transplantation committee has estimated that a substantial proportion of heart attack victims could be saved if heart transplantation were available for these patients on demand $\mathrm{d}^{4}$. This is a particularly attractive prospect given the large fraction of potentially transplantable hearts that currently cannot be matched ${ }^{79,92}$, which could be used to establish a heart bank. Further advancement of banking, assessment, and repair capabilities could allow this approach to benefit ever-larger patient populations.

The ability to save organs not immediately matched could be useful in live donation as well. In the recent innovation of live-kidney-donor chains, in which a patient who has found a willing donor (e.g., a friend or relative) whose kidney is not compatible exchanges their donor kidney for a compatible one, transplants are arranged in long chains, so that each patient in the chain receives a compatible kidney. However, chains end when no appropriate recipient can be immediately found for the last donor in the chain, who instead donates to an individual on the deceased-donor waiting list without a corresponding donor to continue the chain ${ }^{105,106}$. The opportunity to delay transplantation could create wider opportunities to find a donor-recipient pair who can continue the chain, allowing longer chains to be assembled.

Moreover, the ability to bank organs can aid in the development of technologies that could be game-changers for transplantation. For instance, a diverse array of immune tolerance induction approaches could overcome graft rejection while largely eliminating the need for immune suppression. Currently, all successful clinical trials involve living donors, so that tolerance induction treatments can be initiated before transplantation ${ }^{4-50}$. Temporary banking of donor organs could enable tolerance induction for deceased donor organs (the vast majority of transplants) as well, by allowing the required pretransplant preparative regimen to be administered to recipients before the organ transplant. This could give the patient's immune system time to adapt to the donor's antigens before transplantation, and it would also provide time to evaluate the success of tolerance induction protocols in a matched patient before transplantation.

Meanwhile, longer-term efforts to create lab-grown organs by tissue engineering or xenotransplantation of 'humanized' donor animal organs would be aided by the ability to bank inventories to make these approaches practical and cost effective at scale. With advances in immune tolerance induction ${ }^{22}$ and the advent of CRISPR-Cas9 gene editing methods that open the possibility of more complex genetic engineering of donor organs to make them less vulnerable to recipient immune rejection ${ }^{107}$, xenotransplantation could potentially offer a vast new source of transplant organs. But attainment of an engineered organ capable of engraftment and survival remains years away, and the investments required for clinical xenotransplantation are tremendous; large, centralized facilities would be required to produce transplant organs at scale, making costeffective manufacturing and distribution a major concern unless these organs can be banked ${ }^{23}$. Similarly, shelf life has been widely recognized as a key bottleneck in the progress of tissue engineering $6,108,109$.

\section{Challenges in complex tissue preservation}

The same technologies that promise to transform vital organ preservation also advance the preservation of a vast array of tissue systems and address a large breadth of public health needs. Inadequate tissue preservation capabilities are a constraint on basic and preclinical biomedical research aimed at addressing major illnesses, drug testing and drug development, trauma care, stockpiling of 
Table 3 Unmet needs for organ preservation

\begin{tabular}{|c|c|}
\hline Area of biomedicine & Example of public health need \\
\hline Organ transplantation & $\begin{array}{l}\text { Almost } 70 \% \text { of US donor hearts go untransplanted, largely due to preservation limits on assessment and } \\
\text { matching2,38,79,92,170 }\end{array}$ \\
\hline Cancer treatment and fertility & $\begin{array}{l}\text { Ovary banking can save fertility/hormone balance in } 140,000 \text { girls and young women diagnosed with cancer and } \\
\text { potentially exposed to chemo- and radiotherapy in the United States each year } 117\end{array}$ \\
\hline Emergency preparedness & $\begin{array}{l}\text { Banked bone marrow and cord blood could benefit }>10,000 \text { patients after a nuclear accident or attack }{ }^{130,171} \text { as } \\
\text { well as } 14,000 \text { US patients each year suffering acute injury who would benefit from a transplant } 172\end{array}$ \\
\hline Limb recovery and transplantation & 30,000 traumatic amputations per year in the United States; two-thirds of victims are children and young adults ${ }^{133}$ \\
\hline Basic medical research & $\begin{array}{l}\text { Human tissue would be a superior model to the } 100 \text { million mice and rats used in research each year }{ }^{173} \text {; tissue } \\
\text { banking advances are critically needed to aid approaches seeking to treat malignancies }{ }^{174} \text {, neurodegenerative } \\
\text { diseases }{ }^{175} \text {, and other disorders }\end{array}$ \\
\hline Trauma care & $\begin{array}{l}30,000 \text { patients admitted to specialized US burn units each year }{ }^{176} \text {. After a nuclear accident/attack, and estimated } \\
\sim 3 \% \text { of the skin grafts required would currently be available }{ }^{177}\end{array}$ \\
\hline Tissue engineering and regenerative medicine & Shelf life of regenerative medicine products, a sector with a predicted $>\$ 500$-billion market by 2025178 \\
\hline Drug discovery & $\begin{array}{l}\text { Banked human tissue would benefit pre-clinical drug testing and potentially improve low efficiency of drug } \\
\text { development } 179,180\end{array}$ \\
\hline
\end{tabular}

medical countermeasures for large-scale public health emergencies, fertility restoration, as well as the advancement of tissue engineering and regenerative medicine (Table 3 ).

Tissue engineering and regenerative medicine. Current preservation limits present major challenges for the clinical translation of tissue engineering breakthroughs. Without the ability to lengthen shelf life, any firm attempting to develop biomanufactured tissue products lacks capabilities for batch manufacturing and distribution, while also facing difficulties adjusting to changing demand $8,19,24,110,111$. Short product shelf life also prevents implementation of some methods for quality control for tissue and organ products, adding substantial cost and risk ${ }^{8,19,24,111}$.

Opportunities abound to enhance banking capabilities for tissue engineering. For instance, successful cryopreservation of a 2.3 liter biomass consisting of encapsulated liver spheroids for use in a bioartificial liver device may stimulate research on other large-volume tissue-engineered products $^{112}$. These challenges have led the US Commerce Department, US Department of Defense (DoD), and the US government's Multi-Agency Tissue Engineering Sciences working group coordinating tissue engineering research support across the NIH, NSF, the US National Institute of Standards and Technology, the DoD, and other science agencies, to identify preservation as one of the key bottlenecks in tissue engineering efforts ${ }^{6,108,109}$. For instance, a new Advanced Tissue Biofabrication Manufacturing Innovation Institute announced at the June 2016 White House Organ Summit has a major focus on advancing organ preservation $^{113}$; the solicitation calls for preservation technologies to enable biomanufacturing to move from unscalable, just-in-time manufacturing to scalable models using off-the-shelf tissues ${ }^{109}$. Likewise, potential future initiatives under the Defense Innovation Unit-Experimental (http://www. diux.mil) in the areas of biofabrication, tissue engineering, regenerative medicine, and tissue-based chip devices will all likely require capabilities emerging from organ and tissue preservation advances.

Protection of reproductive tissue in cancer patients. Organ and tissue banking could also become a staple of cancer care for children and young adults. Ovary, uterus, and testis banking could be used to restore fertility and hormone balance to the 140,000 childhood and young adult cancer survivors in the United States each year ${ }^{27,114-117}$ and hundreds of thousands more each year worldwide. Reproductive organs are highly sensitive to injury from chemotherapy and radiation, often leaving survivors of childhood and young adult cancer infertile and with altered endocrine function, resulting in lifelong sexual and psychological side effects ${ }^{27,117,118}$. These complications could be prevented by saving and banking reproductive organs and tissue before treatment, then re-implanting them afterward $27,28,119,120$.
Thus far, $>60$ healthy offspring have been born to women who banked ovarian tissue before their first sterilizing cancer treatment ${ }^{121-123}$. Recently, whole sheep ovaries have been cryopreserved and reimplanted, and the sheep have gone on to produce healthy offspring ${ }^{27}$. Additional research can make ovary banking clinically feasible and yield insights applicable to banking testicular tissue, whole testes, and larger organs. With $>1$ million survivors of childhood and young adult cancer living in the United States alone (spanning roughly two generations $)^{118,124}$, it is reasonable to estimate that reproductive organ and tissue banking could become the standard of care for millions of future cancer patients worldwide in the coming decades.

Countermeasures for public health emergencies. Advances in the preservation of many tissues are needed for trauma care, particularly to incorporate regenerative medicine therapies into strategic national stockpiles maintained by the United States' interagency Public Health Emergency Medical Countermeasures Enterprise for natural disasters, nuclear accidents or attacks, chemical and biological weapons, and other large-scale public health threats. For instance, radiological threats stemming from nuclear accidents or attacks have led the US Biomedical Advanced Research and Development Authority (BARDA), charged with procuring medical countermeasures for the strategic national stockpile, to search for measures that can treat radiation injury ${ }^{125}$. A 10-kiloton nuclear blast could cause acute radiation injury in $>1$ million people across a $>10$-mile radius. Large quantities of stockpiled bone marrow, cord blood, and other sources of hematopoietic stem cells could be used either to permanently replace irreparably damaged bone marrow or to serve as a 'bridge' until the recovery of autologous hematopoiesis ${ }^{126}$. The blast from such an event could cause burns and/or trauma combined with radiation exposure in over 45,000 victims $^{127}$, necessitating skin grafts for severe burns ${ }^{128,129}$, and blood vessel grafts for extremity injuries ${ }^{130}$. Similar need for on-demand bone marrow and skin could also arise from the use of mustard gas or other exfoliants. Similarly, a large supply of banked human tissue-particularly liver, kidney, brain, or heart slices_could be a critical resource for the rapid study of novel bioagents and development of medical countermeasures for biological and chemical terrorism threats.

Tissue preservation and banking advances are needed to incorporate these and other treatments into strategic national stockpiles. For instance, precision-cut tissue slices can currently be cultured only for a matter of days, precluding standardization in preparation and ondemand use to address bioterrorism threats ${ }^{131}$. Shortages of skin for use on demand have led both BARDA and the US military to look for 
Table 4 Proofs of principle already exist for each pillar of organ and tissue preservation

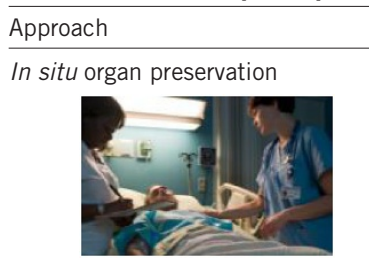

Examples of proof-of-principle discoveries

- Mild hypothermia in deceased kidney donors shown to reduce delayed graft function ${ }^{137}$

- Hypothermic blood substitution protects from prolonged ischemia in trauma models ${ }^{181-183}$

- Treatment of donor with dopamine decreases kidney rejection and improves graft survival ${ }^{138}$

- Cooperative donor management has been associated with more organs transplanted ${ }^{139}$

Ex vivo organ life support

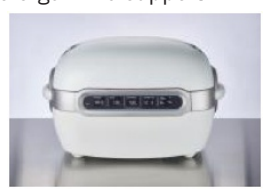

High subzero preservation

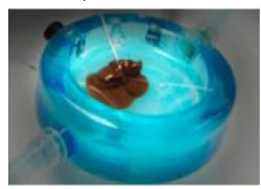

Programmed metabolic suppression - Arctic wood frog, mammals, other species can initiate regulated metabolic arrest 29,31

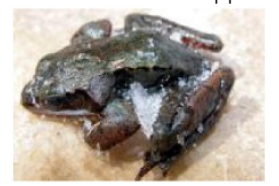

Cryopreservation

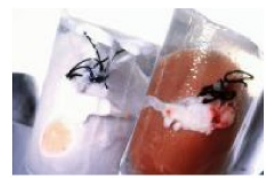

- Hypothermic perfusion devices have improved kidney preservation outcomes ${ }^{33-35,37}$

- Normothermic machine perfusion used in hundreds of heart 38 and lung transplants $36,184,185$

- Subnormothermic machine perfusion used as platform for assessment ${ }^{90}$, cooling 40

- Ex vivo perfusion successfully used as platform to repair marginal organs ${ }^{67}$

- At least 45 supercooling species (including mammals) tolerate temperatures as low as $-14{ }^{\circ} \mathrm{C}^{186}$

- Arctic wood frog can enter suspended animation as low as $-20^{\circ} \mathrm{C}$ for weeks to months 29

- Rabbit kidneys successfully cooled to $-45^{\circ} \mathrm{C}$ before transplantation, sustaining life 26

- Supercooling at $-6{ }^{\circ} \mathrm{C}$ has extended liver preservation times three- to fourfold in rats 40,65

- Genetic and biochemical studies have revealed mechanisms conserved in humans ${ }^{30-32}$

- Pharmacologically induced 'suspended animation' has been demonstrated in mammals 187

- >60 healthy human offspring conceived from cryopreserved ovarian tissue ${ }^{188,189}$ for weeks

- Cryopreserved whole sheep ovaries have been transplanted, producing healthy offspring 27

- Rabbit kidney successfully cryopreserved at $-140^{\circ} \mathrm{C}$ and transplanted, supporting life 68

- Human cells, embryos and some tissues have been cryopreserved for decades ${ }^{6,7}$

- Successful transplantation of whole rat hindlimbs ${ }^{190}$ and replantation of partial rat hindlimbs ${ }^{191}$ following cryopreservation

- Ice-free cryopreservation has led to breakthroughs in banking of tissues for transplantation (e.g., blood vessels, cartilage and corneas) ${ }^{192-195}$

- Research community has codified remaining sub-challenges for organ cryopreservation 6,7

Photo credits: "Programmed metabolic suppression”: J.M. Storey, Carleton University; “Cryopreservation”: G.M.F.

biomanufacturing solutions to stockpile large quantities of skin for combat or emergencies, yet for both groups short tissue shelf life has been cited as a limiting factor ${ }^{25,129,130}$. Cryopreservation has enabled the banking and subsequent transplantation of both bone marrow and skin, but the current state of the art results in some loss of viability ${ }^{128,132}$. In the case of bone marrow banking, improvements to cryopreservation methods can also reduce the incidence of complications after transfusion ${ }^{132}$. Thus, preservation advances would help address large public health needs for these tissues. For entities such as the DoD and BARDA to successfully leverage advances in regenerative medicine, preservation research is a necessity; the nature of emergency response dictates that banked tissues must be available for off-the-shelf use.

Transplantation for acute injuries. Preservation advances could also dramatically increase patient access to transplantation or recovery of vascularized composite tissues, such as limbs, hands, or faces after traumatic injury. For example, roughly 30,000 traumatic amputations occur per year in the United States, over two-thirds in children and young adults; it has been estimated that there will be $>900,000$ survivors of traumatic amputation living in the United States by $2020^{133}$.

Extending preservation capabilities for recovered limbs can allow a greater number to be reattached, and in the past 15 years it has become possible to transplant hands, faces, and whole limbs from deceased donors $^{44-46,134}$. Although ample donor pools are already available, these procedures are still not routine-largely because matching must be done very quickly (for both cosmetic and immunological criteria) and patients face complications from immunosuppression ${ }^{134}$. As discussed, preservation can address both of these challenges, playing a pivotal role in providing access to hand, limb, and face transplantation for tens of thousands of new patients each year.

\section{An integrated approach to preservation}

A growing body of evidence indicates that a transformation in organ and tissue preservation is now achievable. Recent promising discoveries include organ cryopreservation and subzero cooling, perfusion, interventions before organ and tissue recovery, and adaptations that allow dozens of species in nature to enter suspended animation at subfreezing temperatures (Table 4). Together, these approaches form a blueprint for a leap forward in preservation capabilities, centered on a combination of two promising strategies:

1. Providing organ 'life support' by recapitulating aspects of the organ's healthy physiological environment.

2. Effectively controlling biological time by slowing or halting metabolism to decrease the rate of deterioration.

Progress on both fronts is needed because each preservation approach involves tradeoffs often requiring the application of combined strategies 


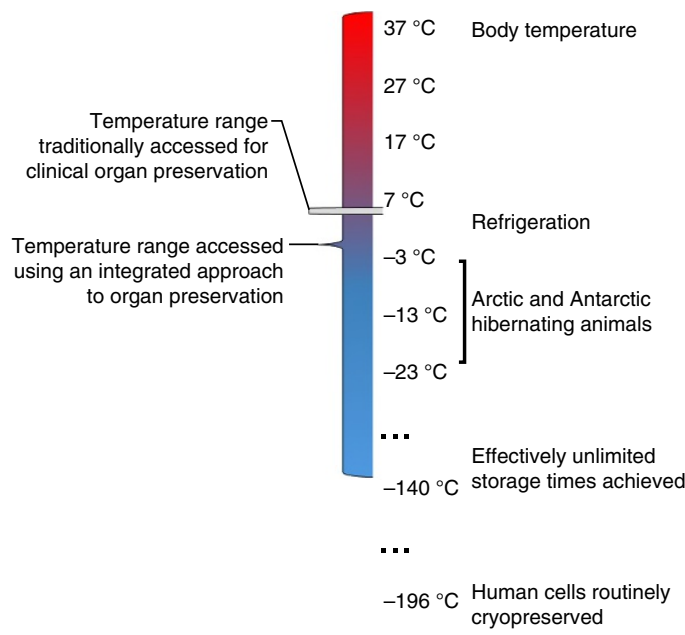

Figure 4 An integrated approach to organ and tissue preservation would combine multiple preservation conditions and temperature ranges, drawing on the strategies found in Table 4. Thus, when called for, differing preservation modalities could be used during successive stages of the preservation process, accessing a much wider range of temperatures and conditions than are currently used in conventional organ preservation. For instance, transplant organs could be held at subnormothermic temperatures during pharmacological pre-conditioning for cryopreservation, then cooled to cryogenic temperatures for transport or banking, then returned to near-normothermic temperatures for functional assessment. Many combinations are conceivable based on the diverse proof-of-principle discoveries; the optimal preservation protocol will most likely vary according to tissue type and application.

in the same organ or tissue. For instance, slowing organ deterioration for extended preservation periods can be achieved by lowering organ temperature and metabolic rates, but this also entails the loss of normal organ function and opportunities for beneficial interventions, such as organ assessment, repair, and functional augmentation (Table 2).

Thus, we must begin to think about the aim of preservation not as the pursuit of a singular 'best' environment to keep a particular organ or tissue healthy on its way to transplantation (or use in research), but as an 'integrated' process during which the organ or tissue traverses multiple preservation conditions and temperature ranges that are used synergistically (Fig. 4). To make an integrated approach to preservation successful, we must combine and advance a family of research areas that includes cryopreservation ${ }^{7}$, programmed metabolic suppression ${ }^{31}$, subzero preservation and supercooling ${ }^{135}$, and perfusion and ex vivo maintenance at a variety of temperatures, ranging from hypothermia (refrigeration) to normothermia (body temperature) ${ }^{34,35,37,136}$, and donor management before organ and tissue recovery ${ }^{137-139}$. The discoveries noted in Table 4 have provided various proofs of principle for using these approaches in organ and tissue preservation. They have historically been relatively siloed, despite the fact that they are complementary and often synergistic 6 ,7,26,31,40,87,91,137.

Advancing organ and tissue preservation through an integrated approach has become an achievable goal, as the past decade has seen an explosion of technologies enabling us to understand and intervene in human physiology at the tissue and organ level. Advances in cellular and tissue imaging ${ }^{140-142}$, organoids, organs on a chip and regenerative medicine ${ }^{13}$, high-throughput assays and sequencing readouts ${ }^{143}$, miniaturization and microfluidics ${ }^{144}$, nanotechnology ${ }^{145,146}$, and molecular engineering and gene editing ${ }^{147-152}$ can all be harnessed to galvanize research into the fundamental biology of tissue and organ cryopreservation, discover novel cryoprotectants, and develop new preservation strategies. This creates exciting prospects for translating the 'suspended animation' programs of animals, such as the arctic ground squirrel ${ }^{153}$ and even tardigrade ${ }^{154}$, into tools for organ and tissue preservation. This decade has also seen rapid advances in ex vivo perfusion platforms ${ }^{33,34,36-38,41,66}$, which can be adapted to recapitulate aspects of an organ's in vivo environment, condition it for storage or transport in a hypometabolic state, or enhance recovery from stresses experienced during donor death or the preservation period $40,155-158$. By building on, and combining, these innovations from different disciplines, we are now poised to create a new generation of organ and tissue preservation capabilities driven by both public and private sector funding (Box 1).

\section{Catalyzing breakthroughs}

So far, the very features that make preservation a foundational and high-impact research area have hindered its progress in the absence of coordinated support. The vast need to increase organ and tissue availability is spread across many areas of medicine and public health (Table 3) - and ultimately stakeholder groups. For instance, over $80 \%$ of NIH's budget goes to institutes with missions tied to unmet preservation needs, encompassing 15 different institutes ${ }^{24}$. This makes organ and tissue preservation research a nearly universal concern, yet it is not the focus of any major funding body.

The research expertise needed is similarly dispersed. Organ and tissue preservation is quintessentially a 'convergence technology', integrating device engineering, applied mathematics, organic and inorganic chemistry, thermodynamics and biophysics, biochemistry and chemical biology, materials science, nanotechnology and molecular engineering, as well as molecular and cell biology $6,143,159$. This creates special challenges, as the institutions supporting science and engineering research have historically been divided according to research discipline ${ }^{159}$. For example, it can be inherently difficult to fund an ambitious preservation project because of the inability to assemble an NIH study section that can address all aspects of such a cross-disciplinary grant proposal-even if all the research expertise to propose such a project comes together in the first place. The nature of organ and tissue preservation demands coordination among a large number of actors spanning many research communities, science agencies, industries, and stakeholder organizations.

This coordination is beginning to take shape. For instance, the NSF-supported technology roadmapping process for organ banking and bioengineering, involving representatives from multiple agencies, including NIH, NSF, the US Food and Drug Administration, the DoD, and other agencies, along with dozens of academic institutions, identified $>20$ surrounding research areas that can be applied to accelerate progress on organ cryopreservation and recommended scientific and institutional strategies to enable organ banking ${ }^{6}$. Similarly, two US Health Resources and Services Administration-funded consensus conferences recently identified untapped opportunities for in situ preservation of organs through donor management ${ }^{160}$. This set the stage for a National Academy of Medicine (Washington, DC, USA) study this year aiming to develop a national infrastructure that will foster donor management research in the United States (http://www. ishlt.org/ContentDocuments/2016DecLinks_Nelson.html). At the June 2016 White House Organ Summit ${ }^{113}$, the Organ Preservation Alliance (of which S.G. and J.K.L. are directors) announced that the alliance is leading a coalition of organizations to study the public health needs, scientific opportunities, and institutional challenges in advancing organ and tissue preservation. The stakeholder groups, which to date include the Association of Organ Procurement Organizations (McLean, VA, USA), the American Society of Mechanical Engineers 


\section{Box 1 Burgeoning public and private sector interest in preservation}

The White House recently announced an upcoming Summit on Organ Banking through Converging Technologies to be held at the Harvard Medical School's Martin Conference Center in August (http://obs2017.obs2017.org/en/). This will be the first scientific consensus-building conference to map out how these and other technologies can be applied systematically to overcome remaining organ preservation challenges. Both basic and translational preservation research seems to be positioned to benefit from rapidly advancing platform technologies. Indeed, the past 3 years have seen a wave of new biotech companies in the organ and tissue preservation space, capitalizing on a small fraction of the opportunities that have emerged. Supported by multiple grant solicitations from the DoD and substantial funding from $\mathrm{NIH}$, these firms are pursuing strategies such as programmed hypometabolism, biomimetic nanoscience, radiofrequency-based 'nanowarming,' isochoric preservation, subnormothermic perfusion, and high-subzero temperature preservation (http://firstround.com/; http://x-therma.com/; https://www.sbir.gov/sbc/sylvatica-biotech-inc) ${ }^{196-198}$. Much of the current focus is on banking and subzero preservation; in this respect, the synergy between these technologies and ex vivo perfusion platforms (Tables 2 and 4 ) $6,7,26,40,41,87,91$ means they benefit from — and enhance the value of - the substantial investments made in ex vivo perfusion in recent years ${ }^{199-202}$

(New York), the Society for Cryobiology (Luton, UK), and others, will work together to craft a cohesive strategy to advance organ and tissue preservation on all fronts ${ }^{161}$. The need for a concerted effort to remove logistical barriers in organ and tissue replacement has also been emphasized in international efforts, for instance, in a recent strategic plan for organ and tissue donation in Canada developed by more than 140 stakeholder organizations ${ }^{162}$.

Initiatives aiming to encourage coordination have already borne fruit in the form of collaborative research efforts that have sprung up around them. In 2015, three DoD small business grant solicitations, targeted toward complex tissue preservation and banking ${ }^{163-165}$ (to the authors' knowledge, the first US grant solicitations on this topic), yielded applications from 35 teams consisting of $>100$ laboratories across industry and academia - a virtually unprecedented response for the funding mechanism used. The DoD increased its support with three more grant solicitations in $2016^{130,166,167}$, largely as a result of the abundance of strong proposals during the previous year from cross-disciplinary teams.

Although this demonstrates the wealth of untapped opportunities in organ and tissue preservation research, active and centralized networking among research laboratories also played a substantial role in the strong response. Another successful effort to bolster research coordination is the Charlotte Banks research initiative at the University of North Carolina, Charlotte, which developed out of discussions at the first global Organ Banking Summit in 2015 in Washington, DC. The initiative aims to cryopreserve living thick tissues by coordinating research among almost a dozen laboratories in vascular biology, nanotechnology, materials science, machine perfusion, computational physics, thermodynamics, and other areas (https://eng-resources. uncc.edu/charlottebanks/). In response to the 2016 White House Organ Summit and Emerging Technologies in Organ Preservation roundtable on Capitol Hill, the American Society of Transplantation has launched a community of practice to advance organ and tissue preservation, in partnership with the Organ Preservation Alliance (https://www.myast.org/about-ast/white-house-highlights-asts-newinitiative-organ-preservation-alliance).

Beyond these promising first steps, several additional mechanisms could be used to accelerate progress. Ambitious but achievable preservation challenges, such as large tissue cryopreservation, may be a good fit for high-stakes, high-publicity incentive prize funding. A standing committee comprising experts and stakeholders from diverse fields is needed to coordinate organ and tissue preservation research. The broader challenge of increasing organ and tissue availability (which includes donation, preservation, manufacturing, and transplantation) is ideally suited for a national or international initiative on the scale of the NIH BRAIN Initiative or Human Genome Project, given the inherent complexity of the remaining scientific challenges and the coordination needed, the increasingly important role of regenerative medicine, and the enormous potential of organ and tissue replacement to improve human health.

Organ and tissue preservation has become fertile ground for the application of existing knowledge, talent and research tools. Opportunities abound for diverse (and often converging) fields to provide innovative solutions, but institutional challenges remain and mechanisms to facilitate wider collaboration are needed. If we meet these challenges and build on the scientific proofs of principle that already exist, we may enter a new era of organ and tissue preservation in the coming years-benefiting millions of patients globally and changing the course of many domains of public health.

\section{ACKNOWLEDGMENTS}

The lead authors owe thanks to many who helped make this article possible: the Thiel Foundation, the Society for Cryobiology, the American Society of Mechanical Engineers, Virginia Commonwealth University, and New Organ for supporting the events that helped develop the growing dialog; the NSF for funding the development of a beta Roadmap to Organ Banking and Bioengineering, and the DoD for funding the development of an Organ Banking Report, each of which has contributed heavily to the content of this article; L.A. acknowledges DARPA's Service Chief Fellows Program for enabling a major 'Organs on Demand' workshop, integral to developing the conclusions in this article. The authors thank M. Severs, J. Horwitz, C. Mallory, and J. Lewis for valuable feedback on the presentation of the information herein; the hundreds of participants of the first global Organ Banking Summit, the Roadmap to Organ Banking and Bioengineering Workshop, the White House Organ Banking Roundtable, the DARPA Organs-on-Demand workshop at the US Military Academy, and the Emerging Technologies in Organ Preservation symposium and roundtable discussion on Capitol Hill, along with many other supporters who have each helped outline the needs and opportunities in biopreservation. U.D. acknowledges NIH grant R01EB015776-05. K.U. and J.F.M. acknowledge NIH grant R01 DK107875. J.A.W.E. holds a Canada Research Chair in Thermodynamics. The authors also thank K. Caldwell, V. Morigi, R. Farmanfarmaian, E. Mohamed, M. Rostad, R. El Assal, P. Kilbride, and the rest of the Organ Preservation Alliance team for their support and dedication to making leaps forward in the ability to preserve organs and tissues.

\section{AUTHOR CONTRIBUTIONS}

S.G., J.K.L., and L.A. developed the main conclusions of the article. S.G. and J.K.L. developed the key points discussed with input from all other co-authors. S.G. developed the original concepts that led to the article's creation. J.K.L. developed the structure of the article and wrote the manuscript. S.G., J.K.L., L.A., R.L., A.E.R., G.M.C., J.F.M., D.H.S., A.C., J.A.W., M.R., E.S.B., E.E., B.P., W.P.A.L., G.B., D.M.W., G.E., D.N., J.P.A., K.U., B.S., B.P.W., A.T., G.M.F., K.B.S., B.R., J.B., J.A.W.E., T.K.W., G.J.M., U.D., K.G.M.B., E.J.W., R.N.B., J.G.B., D.G., B.F., Y.R., D.C.K., M.J.T., and M.T. added conclusions, content, and references, critically reviewed the manuscript, and provided input on structure, style and content. S.G., J.K.L., B.S., B.W., and A.T. created the figures and tables.

\section{COMPETING FINANCIAL INTERESTS}

The authors declare competing financial interests: details are available in the online version of the paper. 
Reprints and permissions information is available online at http://www.nature.com/ reprints/index.html. Publisher's note: Springer Nature remains neutral with regard to jurisdictional claims in published maps and institutional affiliations.

1. Jones, B. \& Bes, M. Keeping kidneys. Bull. World Health Organ. 90, 718-719 (2012).

2. Israni, A.K., Zaun, D., Rosendale, J.D., Snyder, J.J. \& Kasiske, B.L. OPTN/SRTR 2012 Annual Data Report: deceased organ donation. Am. J. Transplant. 14 (Suppl. 1), 167-183 (2014).

3. Hoyert, D.L. \& Xu, J. Deaths: preliminary data for 2011. Natl. Vital Stat. Rep. 61, 1-51 (2012)

4. Cooper, D.K. et al. Report of the Xenotransplantation Advisory Committee of the International Society for Heart and Lung Transplantation: the present status of xenotransplantation and its potential role in the treatment of end-stage cardiac and pulmonary diseases. J. Heart Lung Transplant. 19, 1125-1165 (2000).

5. Evans, R.W. in Xenotransplantation (ed. Platt, J.L.) 29-51 (American Society of Microbiology, 2001).

6. Anonymous. Solving Organ Shortage through Organ Banking and Bioengineering https://www.organpreservationalliance.org/roadmap (Organ Preservation Alliance, 2015).

7. Lewis, J.K. et al. The grand challenges of organ banking: proceedings from the first global summit on complex tissue cryopreservation. Cryobiology 72, 169-182 (2016)

8. Fahy, G.M., Wowk, B. \& Wu, J. Cryopreservation of complex systems: the missing link in the regenerative medicine supply chain. Rejuvenation Res. 9, 279-291 (2006)

9. Rothblatt, M. Your Life or Mine: How Geoethics Can Resolve the Conflict Between Public and Private Interests in Xenotransplantation (Ashgate Publishing Company, 2004)

10. Shimazono, $Y$. The state of the international organ trade: a provisional picture based on integration of available information. Bull. World Health Organ. 85, 955-962 (2007).

11. Anonymous. Second Global Consultation in Human Transplantation: Towards a Common Attitude to Transplantation http://apps. who.int/medicinedocs/documents/ s15437e/s15437e.pdf (World Health Organization, 2007).

12. International Summit on Transplant Tourism and Organ Trafficking. The declaration of Istanbul on organ trafficking and transplant tourism. Clin. J. Am. Soc. Nephrol. 3, 1227-1231 (2008).

13. Anderson, J. Increasing Organ Donation Through Education. AAMC Report. (2014).

14. Kumar, K. et al. A smartphone app for increasing live organ donation. Am. J. Transplant. http://dx.doi.org/10.1111/ajt.13961 (2016).

15. Loinaz, C. \& González, E.M. Marginal donors in liver transplantation. Hepatogastroenterology 47, 256-263 (2000).

16. Saidi, R.F. \& Hejazii Kenari, S.K. Challenges of organ shortage for transplantation: solutions and opportunities. Int. J. Organ Transplant. Med. 5, 87-96 (2014).

17. Maggiore, U. et al. Strategies to increase the donor pool and access to kidney transplantation: an international perspective. Nephrol. Dial. Transplant. 30, 217-222 (2015).

18. Jadlowiec, C.C. \& Taner, T. Liver transplantation: current status and challenges. World J. Gastroenterol. 22, 4438-4445 (2016).

19. Khademhosseini, A. \& Langer, R. A decade of progress in tissue engineering. Nat. Protoc. 11, 1775-1781 (2016)

20. Yagi, H. et al. Human-scale whole-organ bioengineering for liver transplantation: a regenerative medicine approach. Cell Transplant. 22, 231-242 (2013).

21. Barkai, U. et al. Enhanced oxygen supply improves islet viability in a new bioartificial pancreas. Cell Transplant. 22, 1463-1476 (2013).

22. Vagefi, P.A., Shah, J.A. \& Sachs, D.H. Progress towards inducing tolerance of pig-to-primate xenografts. Int. J. Surg. 23 Pt B, 291-295 (2015).

23. Reardon, S. New life for pig-to-human transplants. Nature 527, 152-154 (2015)

24. Samadikuchaksaraei, A. Scientific and industrial status of tissue engineering. Afr. J. Biotechnol. 6, 2897-2909 (2007).

25. Alvarez, L.M. Compendium of organ \& tissue banking concepts. DODlive http:// science.dodlive.mil/files/2015/01/Organ-and-Tissue-Banking-Compendium-2015Jan.pdf (2015)

26. Fahy, G.M. et al. Cryopreservation of organs by vitrification: perspectives and recent advances. Cryobiology 48, 157-178 (2004).

27. Campbell, B.K. et al. Restoration of ovarian function and natural fertility following the cryopreservation and autotransplantation of whole adult sheep ovaries. Hum. Reprod. 29, 1749-1763 (2014).

28. Arav, A. et al. Oocyte recovery, embryo development and ovarian function after cryopreservation and transplantation of whole sheep ovary. Hum. Reprod. 20, 3554-3559 (2005).

29. Larson, D.J. et al. Wood frog adaptations to overwintering in Alaska: new limits to freezing tolerance. J. Exp. Biol. 217, 2193-2200 (2014).

30. Storey, K.B. \& Storey, J.M. Metabolic rate depression in animals: transcriptional and translational controls. Biol. Rev. Camb. Philos. Soc. 79, 207-233 (2004).

31. Storey, K.B. \& Storey, J.M. Metabolic rate depression: the biochemistry of mammalian hibernation. Adv. Clin. Chem. 52, 77-108 (2010).

32. Storey, K.B. \& Storey, J.M. Tribute to P. L. Lutz: putting life on 'pause'--molecular regulation of hypometabolism. J. Exp. Biol. 210, 1700-1714 (2007).
33. Wszola, M. et al. One-year results of a prospective, randomized trial comparing two machine perfusion devices used for kidney preservation. Transpl. Int. 26 1088-1096 (2013).

34. Guarrera, J.V. et al. Hypothermic machine preservation in human liver transplantation: the first clinical series. Am. J. Transplant. 10, 372-381 (2010).

35. Moers, C., Pirenne, J., Paul, A. \& Ploeg, R.J. Machine perfusion or cold storage in deceased-donor kidney transplantation. N. Engl. J. Med. 366, 770-771 (2012).

36. Cypel, M. et al. Experience with the first 50 ex vivo lung perfusions in clinical transplantation. J. Thorac. Cardiovasc. Surg. 144, 1200-1207 (2012).

37. Machuca, T.N. \& Cypel, M. Ex vivo lung perfusion. J. Thorac. Dis. 6, 1054-1062 (2014).

38. Messer, S., Ardehali, A. \& Tsui, S. Normothermic donor heart perfusion: current clinical experience and the future. Transpl. Int. 28, 634-642 (2015).

39. Berendsen, T.A. et al. A simplified subnormothermic machine perfusion system restores ischemically damaged liver grafts in a rat model of orthotopic liver transplantation. Transplant. Res. 1, 6 (2012).

40. Berendsen, T.A. et al. Supercooling enables long-term transplantation survival following 4 days of liver preservation. Nat. Med. 20, 790-793 (2014).

41. Ravikumar, R., Leuvenink, H. \& Friend, P.J. Normothermic liver preservation: a new paradigm? Transpl. Int. 28, 690-699 (2015).

42. Rana, A. et al. Survival benefit of solid-organ transplant in the United States. JAMA Surg. 150, 252-259 (2015).

43. Calne, R.Y. et al. Cyclosporin A in patients receiving renal allografts from cadaver donors. Lancet 312, 1323-1327 (1978).

44. Dubernard, J.M. et al. Human hand allograft: report on first 6 months. Lancet 353, 1315-1320 (1999).

45. Dubernard, J.M. et al. Functional results of the first human double-hand transplantation. Ann. Surg. 238, 128-136 (2003).

46. Devauchelle, B. et al. First human face allograft: early report. Lancet $\mathbf{3 6 8}$, 203-209 (2006)

47. Scandling, J.D. et al. Tolerance and chimerism after renal and hematopoietic-cel transplantation. N. Engl. J. Med. 358, 362-368 (2008).

48. Scandling, J.D., Busque, S., Shizuru, J.A., Engleman, E.G. \& Strober, S. Induced immune tolerance for kidney transplantation. N. Engl. J. Med. 365, 1359-1360 (2011).

49. Leventhal, J R et al. Immune reconstitution/immunocompetence in recipients of kidney plus hematopoietic stem/facilitating cell transplants. Transplantation $\mathbf{9 9}$ 288-298 (2015).

50. Szabolcs, P., Burlingham, W.J. \& Thomson, A.W. Tolerance after solid organ and hematopoietic cell transplantation. Biol. Blood Marrow Transplant. 18 (Suppl.), S193-S200 (2012)

51. Goldberg, D., French, B., Abt, P., Feng, S. \& Cameron, A.M. Increasing disparity in waitlist mortality rates with increased model for end-stage liver disease scores for candidates with hepatocellular carcinoma versus candidates without hepatocellular carcinoma. Liver Transpl. 18, 434-443 (2012).

52. Lai, J.C. et al. Frailty predicts waitlist mortality in liver transplant candidates. Am. J. Transplant. 14, 1870-1879 (2014).

53. Anonymous. Organ Procurement and Transplantation Network (OPTN). Nationa Data Reports. US Dept. of Health and Human Services https://optn.transplant. hrsa.gov/data/view-data-reports/national-data/ (accessed 8 July 2016).

54. Knechtle, S.J. et al. Renal transplantation at the University of Wisconsin in the cyclosporine era. Clin. Transpl. 211-218 (1993).

55. Knoll, G. Trends in kidney transplantation over the past decade. Drugs 68 (Suppl. 1), 3-10 (2008).

56. Dunn, J. et al. Causes of graft loss beyond two years in the cyclosporine era. Transplantation 49, 349-353 (1990).

57. Anonymous. in OPTN/SRTR Annual Report 2011 https://srtr.transplant.hrsa.gov/ annual_reports/2011/pdf/2011_SRTR_ADR.pdf (US Department of Health and Human Services, 2011).

58. Morrissey, P.E., Flynn, M.L. \& Lin, S. Medication noncompliance and its implications in transplant recipients. Drugs 67, 1463-1481 (2007).

59. Ladner, D.P. \& Mehrotra, S. Methodological challenges in solving geographic disparity in liver allocation. JAMA Surg. 151, 109-110 (2016).

60. Saunders, M.R. et al. Racial disparities in reaching the renal transplant waitlist: is geography as important as race? Clin. Transplant. 29, 531-538 (2015).

61. Arce, C.M., Goldstein, B.A., Mitani, A.A., Lenihan, C.R. \& Winkelmayer, W.C. Differences in access to kidney transplantation between Hispanic and nonHispanic whites by geographic location in the United States. Clin. J. Am. Soc. Nephrol. 8, 2149-2157 (2013).

62. Thabut, G. et al. Geographic disparities in access to lung transplantation before and after implementation of the lung allocation score. Am. J. Transplant. 12, 3085-3093 (2012)

63. Lysaght, M.J. Maintenance dialysis population dynamics: current trends and longterm implications. J. Am. Soc. Nephrol. 13 (Suppl. 1), S37-S40 (2002).

64. Collins, A.J et al. United States Renal Data System 2011 Annual Data Report: Atlas of chronic kidney disease and end-stage renal disease in the United States. Am. J. Kidney Dis. 59 (Suppl. 1) A7, e1-420 (2012).

65. Bruinsma, B.G. et al. Supercooling preservation and transplantation of the rat liver. Nat. Protoc. 10, 484-494 (2015).

66. Bruinsma, B.G. et al. Subnormothermic machine perfusion for ex vivo preservation and recovery of the human liver for transplantation. Am. J. Transplant. 14, $1400-1409$ (2014) 
67. Vogel, T., Brockmann, J.G. \& Friend, P.J. Ex-vivo normothermic liver perfusion: an update. Curr. Opin. Organ Transplant. 15, 167-172 (2010).

68. Fahy, G.M. et al. Physical and biological aspects of renal vitrification. Organogenesis 5, 167-175 (2009).

69. Bentley, T.S. 2014 US Organ and Tissue Transplant Cost Estimates and Discussion (Milliman, 2014)

70. Abboudi, H. \& Macphee, I.A. Individualized immunosuppression in transplant patients: potential role of pharmacogenetics. Pharmgenomics Pers. Med. 5, 63-72 (2012).

71. Schwartz, A., Schiano, T., Kim-Schluger, L. \& Florman, S. Geographic disparity: the dilemma of lower socioeconomic status, multiple listing, and death on the liver transplant waiting list. Clin. Transplant. 28, 1075-1079 (2014).

72. Brierley, J. \& Hasan, A. Aspects of deceased organ donation in paediatrics. Br. J. Anaesth. 108 (Suppl. 1), i92-i95 (2012).

73. Vranic, G.M., Ma, J.Z. \& Keith, D.S. The role of minority geographic distribution in waiting time for deceased donor kidney transplantation. Am. J. Transplant. 14, 2526-2534 (2014).

74. Sack, K. In discarding of kidneys, system reveals its flaws. The New York Times http://www.nytimes.com/2012/09/20/health/transplant-experts-blame-allocationsystem-for-discarding-kidneys.html (19 September, 2012).

75. Matas, A.J. OPTN/SRTR 2013 Annual Data Report: kidney. Am. J. Transplant. 15 (Suppl. 2), 1-34 (2015).

76. Wigfield, C.H. et al. Successful emergent lung transplantation after remote ex vivo perfusion optimization and transportation of donor lungs. Am. J. Transplant. 12, 2838-2844 (2012).

77. Vilca Melendez, H., Rela, M., Murphy, G. \& Heaton, N. Assessment of graft function before liver transplantation: quest for the lost ark? Transplantation 70, 560-565 (2000)

78. Burdelski, M. et al. Evaluation of quantitative liver function tests in liver donors. Transplant. Proc. 19, 3838-3839 (1987).

79. Khush, K.K., Menza, R., Nguyen, J., Zaroff, J.G. \& Goldstein, B.A. Donor predictors of allograft use and recipient outcomes after heart transplantation. Circ Heart Fail 6, 300-309 (2013).

80. Hoffmann, T. \& Minor, T. New strategies and concepts in organ preservation. Eur. Surg. Res. 54, 114-126 (2015).

81. Reddy, S.P., Brockmann, J. \& Friend, P.J. Normothermic perfusion: a mini-review. Transplantation 87, 631-632 (2009).

82. Cypel, M., Yeung, J.C. \& Keshavjee, S. Novel approaches to expanding the lung donor pool: donation after cardiac death and ex vivo conditioning. Clin. Chest Med. 32, 233-244 (2011).

83. Lv, X., Tan, J., Liu, D., Wu, P. \& Cui, X. Intratracheal administration of p38 $\alpha$ short-hairpin RNA plasmid ameliorates lung ischemia-reperfusion injury in rats. J. Heart Lung Transplant. 31, 655-662 (2012).

84. Jamieson, R.W. \& Friend, P.J. Organ reperfusion and preservation. Front. Biosci. 13, 221-235 (2008)

85. Mohamed, M.S.A. Translational insights on lung transplantation: learning from immunology. Iran. J. Immunol. 12, 156-165 (2015).

86. Cypel, M. et al. Functional repair of human donor lungs by IL-10 gene therapy. Sci. Transl. Med. 1, 4ra9 (2009).

87. Hosgood, S.A., van Heurn, E. \& Nicholson, M.L. Normothermic machine perfusion of the kidney: better conditioning and repair? Transpl. Int. 28, 657-664 (2015).

88. Xue, M. et al. Donor liver steatosis: a risk factor for early new-onset diabetes after liver transplantation. J. Diabetes Investig. 8, 181-187 (2017).

89. Avolio, A.W. et al. Successful use of extended criteria donor grafts with low to moderate steatosis in patients with model for end-stage liver disease scores below 27. Transplant. Proc. 41, 208-212 (2009).

90. Bruinsma, B.G. et al. Metabolic profiling during ex vivo machine perfusion of the human liver. Sci. Rep. 6, 22415 (2016).

91. Whitson, B.A. \& Black, S.M. Organ assessment and repair centers: The future of transplantation is near. World J. Transplant. 4, 40-42 (2014).

92. Shah, M.R., Starling, R.C., Schwartz Longacre, L. \& Mehra, M.R. Heart transplantation research in the next decade-a goal to achieving evidence-based outcomes: National Heart, Lung, And Blood Institute Working Group. J. Am. Coll. Cardiol. 59, 1263-1269 (2012).

93. Perk, S. et al. A metabolic index of ischemic injury for perfusion-recovery of cadaveric rat livers. PLoS One 6, e28518 (2011).

94. Cypel, M. \& Keshavjee, S. The clinical potential of ex vivo lung perfusion. Expert Rev. Respir. Med. 6, 27-35 (2012).

95. van Smaalen, T.C., Hoogland, E.R.P. \& van Heurn, L.W.E. Machine perfusion viability testing. Curr. Opin. Organ Transplant. 18, 168-173 (2013).

96. Machuca, T.N. et al. Protein expression profiling predicts graft performance in clinical ex vivo lung perfusion. Ann. Surg. 261, 591-597 (2015).

97. US Centers for Disease Control and Prevention. Investigation of rabies infections in organ donor and transplant recipients-Alabama, Arkansas, Oklahoma, and Texas, 2004. MMWR Morb. Mortal. Wkly. Rep. 53, 586-589 (2004).

98. Anonymous. CDC confirms rabies death in organ transplant recipient. $C D C$ Newsroom https://www.cdc.gov/media/releases/2013/s0315_rabies_organs.html (2013)

99. Anonymous. HIV transmitted from a living organ donor-New York City, 2009. MMWR Morb. Mortal. Wkly. Rep. 60, 297-301 (2011).

100. Fishman, J.A. \& Grossi, P.A. Donor-derived infection-the challenge for transplant safety. Nat. Rev. Nephrol. 10, 663-672 (2014).
101. Lee, J.C. \& Christie, J.D. Primary graft dysfunction. Clin. Chest Med. 32, 279-293 (2011).

102. Chen, X.-B. \& Xu, M.-Q. Primary graft dysfunction after liver transplantation. Hepatobiliary Pancreat. Dis. Int. 13, 125-137 (2014).

103. Kobashigawa, J. et al. Report from a consensus conference on primary graft dysfunction after cardiac transplantation. J. Heart Lung Transplant. 33, 327-340 (2014).

104. Mendelson, K.G. \& Fallat, M.E. Pediatric injuries: prevention to resolution. Surg. Clin. North Am. 87, 207-228, viii (2007).

105. Ashlagi, I., Gilchrist, D.S., Roth, A.E. \& Rees, M.A. Nonsimultaneous chains and dominos in kidney-paired donation-revisited. Am. J. Transplant. 11, 984-994 (2011).

06. Anderson, R., Ashlagi, I., Gamarnik, D. \& Roth, A.E. Finding long chains in kidney exchange using the traveling salesman problem. Proc. Natl. Acad. Sci. USA 112 663-668 (2015).

107. Cowan, P.J. \& Tector, A.J. The resurgence of xenotransplantation. Am. J. Transplant. http://dx.doi.org/10.1111/ajt.14311 (2017).

108. Anonymous. Advancing Tissue Science and Engineering https://webarchive.library. unt.edu/eot2008/20080916012251/http://tissueengineering.gov/advancing tissue science \& engineering.pdf (Multi-Agency Tissue Engineering Sciences (MATES) Interagency Working Group, 2007)

109. Anonymous. Funding opportunity announcement: Advanced Tissue Biofabrication Manufacturing Innovation Institute (ATB-MII) https://www.grants.gov/web/grants/ view-opportunity.html?oppld=284612 (US Dept. of Defense, Dept. of the ArmyMateriel Command, 2016)

110. Bradbury, J. Of tardigrades, trehalose, and tissue engineering. Lancet 358, 392 (2001).

111. Ratner, B. What are the opportunities in the field of tissue engineering/regenerative medicine? Workshop on tissue engineering and regenerative medicine. (US Department of Health and Human Services, 28 March 2003).

112. Kilbride, P. et al. Spatial considerations during cryopreservation of a large volume sample. Cryobiology 73, 47-54 (2016).

113. Pondrom, S. White House holds summit on organ transplantation. Am. J. Transplant. 16, 2241-2242 (2016).

114. Jeruss, J.S. \& Woodruff, T.K. Preservation of fertility in patients with cancer N. Engl. J. Med. 360, 902-911 (2009).

115. De Vos, M., Smitz, J. \& Woodruff, T.K. Fertility preservation in women with cancer Lancet 384, 1302-1310 (2014)

116. Tomao, F. et al. Special issues in fertility preservation for gynecologic malignancies. Crit. Rev. Oncol. Hematol. 97, 206-219 (2016).

117. Letourneau, J.M. et al. Acute ovarian failure underestimates age-specific reproductive impairment for young women undergoing chemotherapy for cancer. Cancer 118, 1933-1939 (2012).

118. Woodruff, T.K. The emergence of a new interdiscipline: oncofertility. Cancer Treat Res. 138, 3-11 (2007)

119. Grazul-Bilska, A.T. et al. Morphology and function of cryopreserved whole ovine ovaries after heterotopic autotransplantation. Reprod. Biol. Endocrinol. 6, 16 (2008).

120. Courbiere, B. et al. Difficulties improving ovarian functional recovery by microvascular transplantation and whole ovary vitrification. Fertil. Steril. 91 2697-2706 (2009)

121. Donnez, J. \& Dolmans, M.-M. Fertility preservation in women. Nat. Rev. Endocrinol. 9, 735-749 (2013).

122. Donnez, J. et al. Ovarian tissue cryopreservation and transplantation: a review. Hum. Reprod. Update 12, 519-535 (2006).

123. Donnez, J. \& Dolmans, M.-M. Transplantation of ovarian tissue. Best Pract. Res. Clin. Obstet. Gynaecol. 28, 1188-1197 (2014)

124. Anonymous. Cancer Treatment and Survivorship: Facts \& Figures 2014-2015. Special Section: Cancer in Children \& Adolescents https://www.cancer.org/content/ $\mathrm{dam} /$ cancer-org/research/cancer-facts-and-statistics/cancer-treatment-and survivorship-facts-and-figures/cancer-treatment-and-survivorship-facts-andfigures-2014-2015.pdf (American Cancer Society, 2014).

125. US Department of Health \& Human Services. HHS boosts stockpile of products to treat acute radiation syndrome. EMSWORLD http://www.emsworld.com/ news/11178384/hhs-boosts-stockpile-of-products-to-treat-acute-radiationsyndrome (26 September 2013)

126. Stewart, D.L. Preparing Communities for Nuclear Terrorism https://e-reports-ext. IInl.gov/pdf/761273.pdf (Lawrence Livermore National Laboratory, 2013).

127. Knebel, A.R. et al. Allocation of scarce resources after a nuclear detonation: setting the context. Disaster Med. Public Health Prep. 5 (Suppl. 1), S20-S31 (2011).

128. Ben-Bassat, H. Performance and safety of skin allografts. Clin. Dermatol. 23 365-375 (2005).

129. Crosse, M. National Preparedness: Countermeasures for Thermal Burns GAO-12304 http://www.gao.gov/assets/590/588738.pdf (US Government Accountability Office, 2012).

130. Anonymous. On-demand cell and tissue biologics for mass casualty response A16-050 http://www.acq.osd.mil/osbp/sbir/solicitations/sbir20161/army161.pdf (Army SBIR, 2016)

131. de Graaf, I.A.M. et al. Preparation and incubation of precision-cut liver and intestinal slices for application in drug metabolism and toxicity studies. Nat. Protoc. 5, 1540-1551 (2010). 
132. Shu, Z., Heimfeld, S. \& Gao, D. Hematopoietic SCT with cryopreserved grafts: adverse reactions after transplantation and cryoprotectant removal before infusion. Bone Marrow Transplant. 49, 469-476 (2014).

133. Ziegler-Graham, K., MacKenzie, E.J., Ephraim, P.L., Travison, T.G. \& Brookmeyer, R. Estimating the prevalence of limb loss in the United States: 2005 to 2050. Arch. Phys. Med. Rehabil. 89, 422-429 (2008).

134. Kueckelhaus, M. et al. Vascularized composite allotransplantation: current standards and novel approaches to prevent acute rejection and chronic allograft deterioration. Transpl. Int. 29, 655-662 (2016).

135. Zachariassen, K.E. \& Kristiansen, E. Ice nucleation and antinucleation in nature. Cryobiology 41, 257-279 (2000)

136. Barbas, A.S., Goldaracena, N., Dib, M.J. \& Selzner, M. Ex-vivo liver perfusion for organ preservation: Recent advances in the field. Transplant. Rev. (Orlando) 30, 154-160 (2016)

137. Niemann, C.U. \& Malinoski, D. Therapeutic hypothermia in deceased organ donors and kidney-graft function. N. Engl. J. Med. 373, 2687 (2015)

138. Schnuelle, P. et al. Effects of donor pretreatment with dopamine on graft function after kidney transplantation: a randomized controlled trial. J. Am. Med. Assoc. 302, 1067-1075 (2009).

139. Singbartl, K. et al. Intensivist-led management of brain-dead donors is associated with an increase in organ recovery for transplantation. Am. J. Transplant. 11, 1517-1521 (2011).

140. Lee, J.H. et al. Highly multiplexed subcellular RNA sequencing in situ. Science 343, 1360-1363 (2014)

141. Chen, K.H., Boettiger, A.N., Moffitt, J.R., Wang, S. \& Zhuang, X. RNA imaging. Spatially resolved, highly multiplexed RNA profiling in single cells. Science $\mathbf{3 4 8 ,}$ aaa6090 (2015)

142. Chung, K. et al. Structural and molecular interrogation of intact biological systems. Nature 497, 332-337 (2013)

143. Sharp, P. Meeting global challenges: discovery and innovation through convergence. Science 346, 1468-1471 (2014).

144. Huang, Y., Williams, J.C. \& Johnson, S.M. Brain slice on a chip: opportunities and challenges of applying microfluidic technology to intact tissues. Lab Chip 12, 2103-2117 (2012).

145. Manuchehrabadi, N. et al. Improved tissue cryopreservation using inductive heating of magnetic nanoparticles. Sci. Transl. Med. 9, eaah4586 (2017).

146. Bischof, J. 11. Nanowarming: a new concept in tissue and organ preservation. Cryobiology 71, 167 (2015).

147. Boyden, E.S. A history of optogenetics: the development of tools for controlling brain circuits with light. F1000 Biol. Rep. 3, 11 (2011).

148. Zhang, F. et al. The microbial opsin family of optogenetic tools. Cell 147, 1446-1457 (2011).

149. Mali, P. et al. RNA-guided human genome engineering via Cas9. Science 339, 823-826 (2013).

150. Cong, L. et al. Multiplex genome engineering using CRISPR/Cas systems. Science 339, 819-823 (2013)

151. Mojica, F.J.M., Díez-Villaseñor, C., García-Martínez, J. \& Soria, E. Intervening sequences of regularly spaced prokaryotic repeats derive from foreign genetic elements. J. Mol. Evol. 60, 174-182 (2005).

152. Jinek, M. et al. A programmable dual-RNA-guided DNA endonuclease in adaptive bacterial immunity. Science 337, 816-821 (2012).

153. Liu, Y. et al. Genomic analysis of miRNAs in an extreme mammalian hibernator, the Arctic ground squirrel. Physiol. Genomics 42A, 39-51 (2010).

154. Hashimoto, T. et al. Extremotolerant tardigrade genome and improved radiotolerance of human cultured cells by tardigrade-unique protein. Nat. Commun. 7, 12808 (2016)

155. Limkemann, A. et al. Donor gluconate rescues livers from uncontrolled donation after cardiac death. Surgery 159, 852-861 (2016).

156. Parrish, D. et al. New low-volume resuscitation solutions containing PEG-20k. J. Trauma Acute Care Surg. 79, 22-29 (2015)

157. Magliocca, J.F. et al. Extracorporeal support for organ donation after cardiac death effectively expands the donor pool. J. Trauma 58, 1095-1102 (2005).

158. Brasile, L. et al. Overcoming severe renal ischemia: the role of ex vivo warm perfusion. Transplantation 73, 897-901 (2002).

159. Sharp, P., Jacks, T. \& Hockfield, S. Convergence: The Future of Health http://www. convergencerevolution.net/2016-report/ (Massachusetts Institute of Technology, 2016).

160. Nelson, D.P. Donor Management Research Consensus Conference. Int. Soc. Heart Lung Transplant. Links Newsletter $\mathbf{5}$ https://www.ishlt.org/ContentDocuments/ 2013Nov_Links.html (November 2013).

161. White House. Fact sheet: Obama administration announces key actions to reduce the organ waiting list https://obamawhitehouse.archives.gov/the-press-office/2016/ 06/13/fact-sheet-obama-administration-announces-key-actions-reduce-organ (2016).

162. Anonymous. A strategic plan to improve organ and tissue donation and transplantation performance for Canadians https://blood.ca/sites/default/files/otdtindx-final-c2a.pdf (Canadian Blood Services, 2011).

163. Anonymous. Cryopreservation for regenerative medical applications. A15-059 http://www.acq.osd.mil/osbp/sbir/solicitations/sbir20151/army151.pdf (Army SBIR, 2015)

164. Anonymous. Optimal rewarming solutions for cryopreserved tissue systems. DHP15-014. SBIRSource https://sbirsource.com/sbir/topics/91484 (2015).
165. Anonymous. Optimization of cryoprotectants, cryotherapeutics, and protocols for cryopreservation of large tissue systems. DHP15-013 http://www.acq.osd.mil/ osbp/sbir/solicitations/sbir20151/dhp151.pdf (Defense Health Program SBIR, 2015).

166. Anonymous. Conservation and maintenance of trauma injured tissues for autologous repair and reconstruction. A16-049 http://www.acq.osd.mil/osbp/sbir/ solicitations/sbir20161/army161.pdf (Army SBIR, 2016).

167. Anonymous. Genitourinary tissue repair, restoration and protection: preserving fertility and function in wounded warriors. DHP16-012 http://www.acq.osd.mil/ osbp/sbir/solicitations/sbir20161/dhp161.pdf (Defense Health Program SBIR, 2016).

168. Mathew, J. \& Kratzke, R.A. Lung cancer and lung transplantation: a review. J. Thorac. Oncol. 4, 753-760 (2009)

169. Anonymous. How organs are matched. UNOS https://www.unos.org/transplantation/ matching-organs/?gclid=CjwKEAjwsuK_BRDD9ISR 1 bawwUwSJACbOiixRL bb3ISa3IAx_Otd5EB83n6BYvoUYWkeSid6bg3UKBoC3CLw_wcB (accessed: 13 October 2016).

170. Khush, K.K., Zaroff, J.G., Nguyen, J., Menza, R. \& Goldstein, B.A. National decline in donor heart utilization with regional variability: 1995-2010. Am. J. Transplant. 15, 642-649 (2015).

171. Waselenko, J.K. et al. Medical management of the acute radiation syndrome: recommendations of the Strategic National Stockpile Radiation Working Group. Ann. Intern. Med. 140, 1037-1051 (2004).

172. Anonymous. Blood marrow and cord blood donation and transplantation. HRSA http://bloodcell.transplant.hrsa.gov/ (accessed: 1 January 2016).

173. Carbone, L. What Animals Want: Expertise and Advocacy in Laboratory Animal Welfare Policy (Oxford University Press, 2004).

174. Rogers, J., Carolin, T., Vaught, J. \& Compton, C. Biobankonomics: a taxonomy for evaluating the economic benefits of standardized centralized human biobanking for translational research. J. Natl. Cancer Inst. Monogr. 2011, 32-38 (2011).

175. Dragunow, M. The adult human brain in preclinical drug development. Nat. Rev. Drug Discov. 7, 659-666 (2008).

176. Anonymous. Burn incidence and treatment in the United States: 2016. American Burn Association http://www.ameriburn.org/resources_factsheet.php (accessed: 1 January 2016).

177. DiCarlo, A.L. et al. Radiation injury after a nuclear detonation: medical consequences and the need for scarce resources allocation. Disaster Med. Public Health Prep. 5 (Suppl. 1), S32-S44 (2011).

178. Anonymous. 2020: A New Vision. A Future for Regenerative Medicine https:// medicine.osu.edu/regenerativemedicine/documents/2020vision.pdf (Interagency Federal Working Group on Regenerative Medicine, 2005).

179. Hay, M., Thomas, D.W., Craighead, J.L., Economides, C. \& Rosenthal, J. Clinica development success rates for investigational drugs. Nat. Biotechnol. 32, 40-51 (2014).

180. Cummings, J.L., Morstorf, T. \& Zhong, K. Alzheimer's disease drug-development pipeline: few candidates, frequent failures. Alzheimers Res. Ther. 6, 37 (2014).

181. Taylor, M.J. et al. Asanguineous whole body perfusion with a new intracellular acellular solution and ultraprofound hypothermia provides cellular protection during 3.5 hours of cardiac arrest in a canine model. ASAIO J. 40, M351-M358 (1994).

182. Taylor, M.J. et al. A new solution for life without blood. Asanguineous low-flow perfusion of a whole-body perfusate during 3 hours of cardiac arrest and profound hypothermia. Circulation 91, 431-444 (1995).

183. Rhee, P. et al. Induced hypothermia during emergency department thoracotomy: an animal model. J. Trauma 48, 439-450 (2000).

184. Munshi, L., Keshavjee, S. \& Cypel, M. Donor management and lung preservation for lung transplantation. Lancet Respir. Med. 1, 318-328 (2013).

185. Azevedo, M. Donor lungs ready for transplant is goal of Toronto start-up supported by $\$ 2.6 \mathrm{M}$ from XENiOS. Pulmonary Fibrosis News https://pulmonaryfibrosis news.com/2016/02/26/xenios-invests-2-6-million-in-xor-labs-toronto/ (26 February 2016)

186. Lowe, C.H., Lardner, P.J. \& Halpern, E.A. Supercooling in reptiles and other vertebrates. Comp. Biochem. Physiol. A 39, 125-135 (1971).

187. Blackstone, E., Morrison, M. \& Roth, M.B. H2S induces a suspended animationlike state in mice. Science 308, 518 (2005).

188. Donnez, J. \& Dolmans, M.M. Ovarian cortex transplantation: 60 reported live births brings the success and worldwide expansion of the technique towards routine clinical practice. J. Assist. Reprod. Genet. 32, 1167-1170 (2015).

189. Silber, S., Pineda, J., Lenahan, K., DeRosa, M. \& Melnick, J. Fresh and cryopreserved ovary transplantation and resting follicle recruitment. Reprod. Biomed. Online 30, 643-650 (2015).

190. Arav, A., Friedman, O., Natan, Y., Gur, E. \& Shani, N. Rat hindlimb cryopreservation and transplantation - A step towards "organ banking". Am. J. Transplant. (2017)

191. Wang, Z. et al. Cryopreservation and replantation of amputated rat hind limbs. Eur. J. Med. Res. 19, 28 (2014)

192. Song, Y.C., Khirabadi, B.S., Lightfoot, F., Brockbank, K.G. \& Taylor, M.J. Vitreous cryopreservation maintains the function of vascular grafts. Nat. Biotechnol. 18 296-299 (2000).

193. Taylor, M.J., Brockbank, K.G.M. \& Song, Y.C. in Life in the Frozen State (eds. Fuller, B.J., Lane, N. \& Benson, E.E.) 603-641 (CRC Press, 2004).

194. Abazari, A., Jomha, N.M., Elliott, J.A.W. \& McGann, L.E. Cryopreservation of articular cartilage. Cryobiology 66, 201-209 (2013). 
195. Jomha, N.M. et al. Vitrification of intact human articular cartilage. Biomaterials 33, 6061-6068 (2012).

196. Anonymous. Tissue Testing Technologies. SBIR-STTR https://www.sbir.gov/sbc/ tissue-testing-technologies-Ilc-3 (accessed: 1 January 2016).

197. Anonymous. Ossium Health Inc. Buzzfile http://www.buzzfile.com/business/ Ossium-Health-317-370-7293 (accessed: 1 January 2016)

198. Anonymous, Organ Solutions, LLC. Buzzfile http://www.buzzfile.com/ business/Organ-Solutions,-LLC-617-643-3800 (accessed: 1 January 2016).

199. Anonymous. TransMedics, Inc. announces closing of $\$ 51.2$ million growth financing to transform organ transplant therapy. PRNewswire http://www.prnewswire.com/news-releases/ transmedics-inc-announces-closing-of-512-million-growth-financing-to-transform-organtransplant-therapy-300274937.html (accessed: 28 September 2016).

200. Anonymous. TransMedics, Inc. secures $\$ 36$ million round of financing led by Abrams Capital Management. TransMedics http:/www.transmedics.com/wt/page/ pr_1354044406 (accessed: 28 September 2016).

201. Mathis, K.B. Mayo Clinic adding new lung center. The Daily Record http://www. jaxdailyrecord.com/showstory.php?Story id=545906 (5 August 2015).

202. Anonymous. Company profiles: organ recovery systems. PitchBook http://pitchbook. $\mathrm{com} /$ profiles/organ-recovery-systems-profile-investors-funding-valuation-andanalysis (accessed: 28 September 2016).

1 Organ Preservation Alliance, NASA Research Park, Moffett Field, California, USA. 2Sylvatica Biotech, Inc., Charleston, South Carolina, USA. ${ }^{3}$ Ossium Health, San Francisco, California, USA. ${ }^{4}$ Regenerative Biology Research Group, Cancer and Developmental Biology Laboratory, National Cancer Institute, Bethesda, Maryland, USA. ${ }^{5}$ Walter Reed National Military Medical Center, Bethesda, Maryland, USA. ${ }^{6}$ Department of Chemistry and Life Science, United States Military Academy, West Point, New York, USA. ${ }^{7}$ Department of Chemical Engineering, Massachusetts Institute of Technology, Cambridge, Massachusetts, USA. ${ }^{8}$ Department of Economics, Stanford University, Stanford, California, USA. ${ }^{9}$ Department of Genetics, Harvard Medical School, Boston, Massachusetts, USA. ${ }^{10}$ Division of Transplant Surgery, Department of Surgery, Massachusetts General Hospital, Boston, Massachusetts, USA. ${ }^{11}$ Columbia Center for Translational Immunology, Columbia University Medical Center, New York, New York, USA. ${ }^{12}$ American Society of Transplantation, Mt. Laurel, New Jersey, USA. ${ }^{13}$ Transplantation Research Center, Renal Division, Brigham and Women's Hospital, Harvard Medical School, Boston, Massachusetts, USA. ${ }^{14}$ American Society of Transplant Surgeons, Arlington Virginia, USA. ${ }^{15}$ Comprehensive Transplant Center, Northwestern University Feinberg School of Medicine, Chicago, Illinois, USA. ${ }^{16}$ United Therapeutics, Silver Spring, Maryland, USA. ${ }^{17}$ MIT Media Lab and McGovern Institute, Massachusetts Institute of Technology, Cambridge, Massachusetts, USA. ${ }^{18}$ Association of Organ Procurement Organizations, Vienna, Virginia, USA. ${ }^{19}$ Department of Plastic and Reconstructive Surgery, Johns Hopkins University School of Medicine, Baltimore, Maryland, USA. ${ }^{20}$ Department of Surgery, Division of Plastic Surgery, Brigham and Women's Hospital/Harvard Medical School, Boston, Massachusetts, USA. ${ }^{21}$ Department of Medical Oncology, Dana-Farber Cancer Institute, Harvard Medical School, Boston, Massachusetts, USA. 22Department of Mechanical Engineering and Engineering Science, University of North Carolina at Charlotte, Charlotte, North Carolina, USA. ${ }^{23}$ Department of Transplant Medicine, Nazih Zuhdi Transplant Institute, Integris Baptist Medical Center, Oklahoma City, Oklahoma, USA. ${ }^{24}$ Department of Laboratory Medicine and Pathology, University of Alberta, Edmonton, Alberta, Canada. ${ }^{25}$ Society for Cryobiology, Baltimore, Maryland, USA. ${ }^{26}$ Department of Surgery, Center for Engineering in Medicine, Massachusetts General Hospital, Harvard Medical School, Boston, Massachusetts, USA. ${ }^{27}$ Max Planck Institute of Psychiatry, Munich, Germany. ${ }^{28}$ Department of Radiology, Stanford School of Medicine, Stanford, California, USA. ${ }^{29} 21$ st Century Medicine, Fontana, California, USA. ${ }^{30}$ Institute of Biochemistry, Carleton University, Ottawa, Ontario, Canada. ${ }^{31}$ Department of Mechanical Engineering, University of California Berkeley, Berkeley, California, USA. ${ }^{32}$ Department of Mechanical Engineering, University of Minnesota, Minneapolis, Minnesota, USA. ${ }^{33}$ Department of Chemical and Materials Engineering, University of Alberta, Edmonton, Alberta, Canada. ${ }^{34}$ Division of Obstetrics and GynecologyReproductive Science in Medicine, Northwestern University Feinberg School of Medicine, Chicago, Illinois, USA. ${ }^{35}$ Asymptote Ltd., Cambridge, UK. ${ }^{36}$ Department of Electrical Engineering (by courtesy), Stanford, California, USA. ${ }^{37}$ Department of Bioengineering, Clemson University, Clemson, South Carolina, USA. ${ }^{38}$ Department of Microbiology and Immunology, Indiana University School of Medicine, Indianapolis, Indiana, USA. ${ }^{9}$ Department of Chemistry and Biomolecular Sciences, University of Ottawa, Ottawa, Ontario, Canada. ${ }^{40}$ Department of Biological Sciences, Binghamton University, State University of New York, Binghamton, New York, USA.

${ }^{41}$ Department of Mechanical Engineering, University of Washington, Seattle, Washington, USA. ${ }^{42}$ Division of Surgery \& Interventional Science, University College Medical School, Royal Free Hospital Campus, London, UK. ${ }^{43}$ Department of Mechanical Engineering, Carnegie Mellon University, Pittsburgh, Pennsylvania, USA. ${ }^{44}$ Organ Recovery Systems, Chicago, Illinois, USA. ${ }^{45}$ Department of Surgery, University of Arizona, Tucson, Arizona, USA. ${ }^{46}$ These authors contributed equally to this work. Correspondence should be addressed to J.K.L. (jedd@organpreservationalliance.org). 